Volume 3, Nomor 1, Juni 2020

\title{
PENERAPAN MODEL PEMBELAJARAN PROBLEM BASED LEARNING UNTUK MENINGKATKAN PRESTASI DAN KEAKTIFAN BELAJAR PESERTA DIDIK PADA MATA PELAJARAN KOMPUTER DAN JARINGAN DASAR KELAS X TKJ 1 SMK NEGERI 1 KEMUSU BOYOLALI
}

\author{
Sukamto ${ }^{1}$, Afis Pratama ${ }^{2}$, Handini Arga $\mathrm{DR}^{3}$ \\ SMK Negeri 1 Kemusu Boyolali ${ }^{1}$, Universitas IVET ${ }^{2}$, Universitas IVET ${ }^{3}$ \\ Email : sukamtounik@ymail.com
}

\begin{abstract}
ABSTRAK
Tujuan penelitian ini adalah 1) Meningkatkan kegiatan pembelajaran Komputer dan Jaringan Dasar peserta didik Kelas X TKJ 1 SMK Negeri 1 Kemusu Boyolali agar lebih baik, 2) Meningkatkan dan mendorong keaktifan peserta didik pada mata pelajaran Komputer dan Jaringan Dasar di Kelas X TKJ 1 SMK Negeri 1 Kemusu Boyolali, 3) Mengetahui adanya peningkatan hasil belajar mata pelajaran Komputer dan Jaringan Dasar Peserta didik Kelas X TKJ 1 SMK Negeri 1 Kemusu Boyolali.

Penelitian Tindakan Kelas (PTK) dengan menggunakan 2 siklus, setiap siklus terdiri dari 3 kali pertemuan dimulai dari tahapan perencanaan, pelaksanaan, observasi, dan refleksi. Subjek penelitian ini adalah peserta didik kelas X TKJ 1 SMK Negeri 1 Kemusu Boyolali pada bulan Maret 2019 sampai dengan Juni 2019 dengan jumlah peserta didik 25 (dua puluh lima). Data diperoleh dengan dokumentasi, observasi, dan tes teori. Analisis data digunakan analisis deskriptif prosentase.

Hasil penelitian menunjukkan bahwa (a) Ketuntasan belajar siswa dari kondisi awal atau pra siklus dengan hasil tes yang hanya sebesar $28 \%$ atau 7 siswa dari 25 siswa meningkat menjadi sebesar $48 \%$ atau 12 siswa dari 25 siswa pada siklus I, terjadi peningkatan sebesar $20 \%$ atau 5 anak, dan meningkat ke hasil tes siklus II sebesar $80 \%$ atau 20 siswa dari 25 siswa, yang menunjukan peningkatan sebesar 32\% atau 8 anak. (b) Keaktifan siswa yang masuk dalam kategori "cukup" pada siklus I yaitu sebesar $67 \%$ dan diperbaiki serta meningkat pada siklus II menjadi $87 \%$ yang masuk dalam kategori "sangat baik". (c) Meningkatnya kinerja/ kemampuan guru dalam kategori "cukup" yaitu sebesar 68\% pada siklus I, dan meningkat menjadi kategori "baik" pada siklus II yaitu sebesar 80\%.
\end{abstract}

Kata kunci: problem based learning, komputer dan jaringan dasar

\begin{abstract}
The purpose of this study is 1) Increase the learning activities of Computer and Basic Network of Class X TKJ 1 students of SMK Negeri 1 Kemusu Boyolali to be better, 2) Increase and encourage the activeness of students in Computer and Basic Network subjects in Class X TKJ 1 of SMK Negeri 1 Boyolali Kemusu, 3) Knowing an increase in learning outcomes in Computer and Basic Networking Class X TKJ 1 students of SMK Negeri 1 Boyolali.

Classroom Action Research (CAR) using 2 cycles, each cycle consisting of 3 meetings starting from the stages of planning, implementation, observation, and reflection. The subjects of this study were students of class X TKJ 1 SMK Negeri 1 Kemusu Boyolali in March 2019 to June 2019 with the number of students 25 (twenty-five). Data obtained by documentation, observation, and theory tests. Data analysis used descriptive percentage analysis.

The results showed that (a) completeness of student learning from the initial or pre-cycle conditions with test results of only $28 \%$ or 7 students from 25 students increased to $48 \%$ or 12 students from 25 students in the first cycle, an increase of $20 \%$ or 5 children, and increased to the results of the second cycle test by $80 \%$ or 20 students out of 25 students, which showed an increase of $32 \%$ or 8 children. (b) The activeness of students who fall into the "enough" category in the first cycle is $67 \%$ and is improved and increases in the second cycle to $87 \%$ which falls into the "very good" category. (c) Increased performance / ability of teachers in the "enough" category by $68 \%$ in the first cycle, and increased to the "good" category in the second cycle by $80 \%$.
\end{abstract}

Keywords: problem based learning, computers and basic networks 


\section{PENDAHULUAN}

Pendidikan pada dasarnya berfungsi mengembangkan kemampuan, potensi, dan membentuk watak seseorang menjadi lebih baik. Sekolah adalah salah satu lembaga yang berperan dalam pengembangan kemampuan dan potensi serta pembentukan watak. Pada dasarnya setiap sekolah memiliki lingkungan yang berbeda, bahkan dalam sekolah yang sama namun kelas yang berbeda juga memiliki proses pembelajaran yang berbeda. Dalam suatu proses pembelajaran terdapat permasalahanpermasalahan baik internal maupun eksternal. Permasalahan dihadapi agar mencapai hasil yang lebih baik.

Dilihat dari masalah-masalah tersebut, peneliti mendapatkan beberapa hal yang harus ditingkatkan dalam proses pembelajaran mata pelajaran Komputer dan Jaringan Dasar, yaitu penggunaan sumber belajar, keaktifan pesereta didik, jam pembelajaran di sore hari, hasil ulangan yang rendah, dan metode pembelajaran yang bersifat ceramah, teori dan konvensional sehingga masalah tersebut akan berpengaruh terhadap hasil belajar peserta didik.

Mata pelajaran Komputer dan Jaringan Dasar adalah mata pelajaran penting dalam jurusan Teknik Komputer dan Jaringan karena materi yang diajarkan adalah dasardasar komputer dan jaringan lokal yang kemudian dikembangkan lagi dalam mata pelajaran lain. Berdasarkan hasil ulangan harian mata pelajaran Komputer dan Jaringan Dasar, dalam 1 kelas (25 peserta didik) baru terdapat 7 peserta didik yang sudah mencapai Kriteria Ketuntasan Minimal atau 28\% dan 18 peserta didik belum mencapai nilai Kriteria Ketuntasan Minimal atau $72 \%$ peserta mendapatkan nilai di bawah Kriteria Ketuntasan Minimal dengan penyampaian materi pembelajaran yang secara ceramah, teori dan konvensional karena keterbatasan media dan peralatan.
Peneliti merumuskan masalah penelitian yaitu : (1) Model problem based learning dapat meningkatkan pembelajaran, (2) Model problem based learning dapat meningkatkan keaktifan peserta didik, (3) Model problem based learning agar dapat meningkatkan hasil belajar peserta didik.

Berdasarkan uraian di atas, peneliti bertujuan untuk meningkatkan kegiatan pembelajaran, meningkatkan dan mendorong keaktifan peserta didik serta mengetahui peningkatan hasil belajar mata pelajaran Komputer dan Jaringan Dasar peserta didik kelas X TKJ 1 SMK Negeri 1 Kemusu.

Penelitian ini diharapkan bermanfaat bagi peserta didik dan guru dalam membantu meningkatkan, memahami materi meningkatkan keaktifan, meningkatkan pengalaman tentang pembelajaran model problem based learnig, meningkatkan profesionalisme, kreatifitas dan inovasi dalam proses pembelajaran.

\section{METODE PENELITIAN}

Penelitian ini merupakan penelitian tindakan kelas (PTK) dengan menerapkan Model Kemmis dan Taggart terdapat 4 (empat) komponen penelitian tindakan dalam sistem spiral yaitu (plan), tindakan (act), pengamatan (observe), dan refleksi (reflect) (Darmadi,2011:248) dengan bagan berikut :

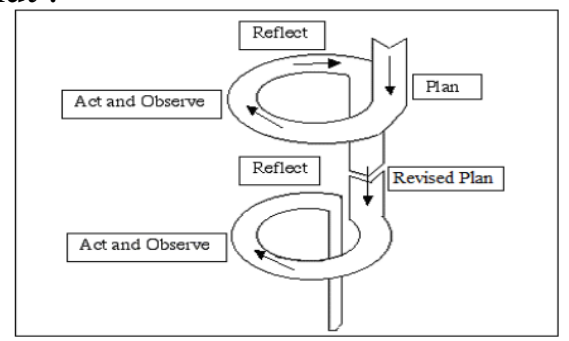

Gambar 1. Siklus Model Kemmis dan Taggart

Penelitian dilakukan pada siswa kelas $\mathrm{X}$ jurusan Teknik Komputer dan Jaringan SMK Negeri 1 Kemusu Boyolali tahun pelajaran 2018/2019 sebanyak 25 siswa, karena melihat hasil pengamatan sementara peneliti melihat hasil belajar siswa pada 
mata pelajaran Komputer dan Jaringan Dasar dalam pembelajaran di kelas X TKJ 1 belum sesuai harapan.

Adapun prosedur yang digunakan dalam penelitian ini merupakan pengembangan PTK berbentuk siklus (cycle). Tiap siklus dilakukan sesuai dengan perubahan kearah peningkatan dan perbaikan proses maupun hasil belajar dengan skema dibawah ini :

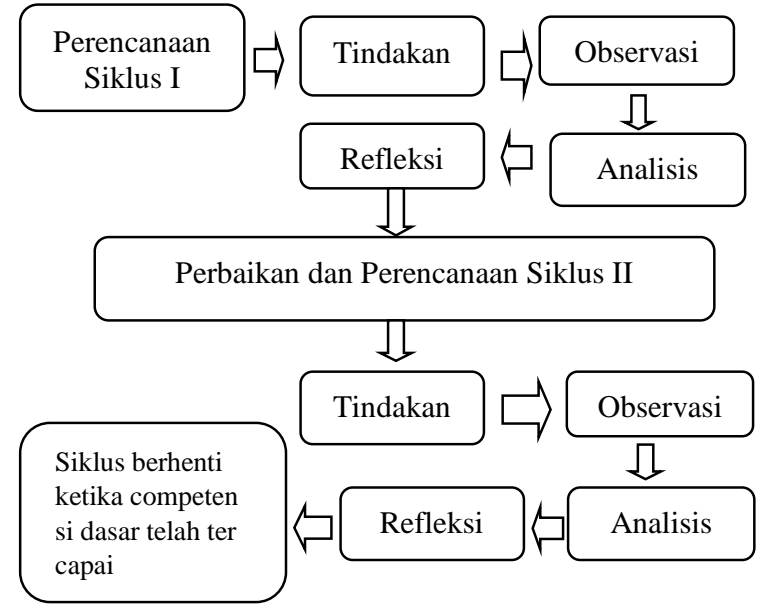

Gambar 2. Bagan siklus kegiatan

Adapun instrumen yang digunakan dalam penelitian ini meliputi: job sheet, report sheet, form penilaian teori, lembar observasi peserta didik, lembar observasi guru.

Data dianalisis secara deskriptif yaitu mengemukakan fakta-fakta dan temuantemuan yang terjadi selama penelitian berlangsung. Analisis data bertujuan untuk melihat apakah terdapat peningkatan hasil belajar. Data hasil belajar diperoleh dari tes setiap ahir siklus I dan II, digunakan untuk mengetahui perkembangan nilai siswa dari sebelum dan sesudah menggunakan metode problem based learning (Suharsimi Arikunto, 2005:264) dengan rumus menghitung rata - rata :

\section{a) Menghitung Rata - Rata Nilai}

$$
\begin{aligned}
& X=\frac{\sum x}{N} \\
& \text { Keterangan: } \\
& X \quad=\text { Rata }- \text { rata nilai }
\end{aligned}
$$

$$
\begin{aligned}
& \sum \boldsymbol{x}=\text { Jumlah keseluruhan nilai } \\
& \boldsymbol{N}=\text { Jumlah siswa }
\end{aligned}
$$

b) Menghitung Ketuntasan belajar

$$
\%=\frac{n}{N}
$$

Keterangan :

$\%=$ Porsentase suatu nilai

$n \quad=$ Jumlah nilai yang tuntas

$N \quad=$ Jumlah seluruh siswa (Ali, 1993:186)

c) Keaktifan siswa dalam pembelajaran

$$
\mathrm{P}=\frac{\text { Jumlah skor yang diperoleh siswa }}{\text { Jumlah seluruh aspek }} \times 100 \%
$$

Keterangan :

$\mathrm{P}=$ Prosentase keaktifann siswa

Skor 1 ; Jika siswa melakukan kegiatan aspek tertentu

Skor 0 : Jika siswa tidak melakukan kegiatan aspek

d) Pengamatan terhadap kinerja guru $\mathrm{P}=\frac{\text { Skor yang diperoleh guru }}{\text { Jumlah skor maksimum }} \times 100 \%$

Keterangan :

$\mathrm{P}=$ Prosentase kinerja guru

Tabel 1. Skala prosentase menurut Suharsimi Arikunto

\begin{tabular}{cc}
\hline Skor nilai & Kategori \\
\hline $80 \%-100 \%$ & Sangat baik \\
\hline $75 \%-79 \%$ & Baik \\
\hline $60 \%-69 \%$ & Cukup \\
\hline $0 \%-59 \%$ & Kurang \\
\hline
\end{tabular}

\section{HASIL DAN PEMBAHASAN}

\section{Hasil}

\section{a) Data Pra Siklus}

Hasil pengamatan sementara yang dilakukan pada siswa kelas $\mathrm{X}$ TKJ 1 SMK Negeri 1 Kemusu menunjukkan hasil ulangan akhir semester gasal tahun ajaran 2018/2019 sebagai berikut : Tabel 2. Prosentase hasil tes pra siklus

\begin{tabular}{ccccc}
\hline $\begin{array}{c}\text { Jumlah } \\
\text { siswa }\end{array}$ & Tuntas & $\begin{array}{c}\text { Tidak } \\
\text { Tuntas }\end{array}$ & $\begin{array}{c}\text { Ketuntasan } \\
(\boldsymbol{\%})\end{array}$ & $\begin{array}{c}\text { Rata- } \\
\text { rata }\end{array}$ \\
\hline 25 & 7 & 18 & 28 & 61,52 \\
\hline
\end{tabular}

Hasil tes pra siklus menunjukan bahwa rata - rata nilai yang mereka peroleh adalah 61,52, sedangkan nilai tersebut masih berada dibawah KKM yaitu 78 . Siswa yang mendapatkan nilai diatas KKM hanyalah 7 anak yang dapat 
disimpulkan nilai ketuntasan hanya mencapai $28 \%$.

\section{b. Hasil Penelitian Siklus I}

Objek pengamatan dilakukan terhadap ketuntasan hasil belajar, keaktifan siswa selama proses pembelajaran berlangsung, dan meningkatnya kegiatan pembelajaran guru/ peneliti, observasi dan evaluasi pada siklus I diperoleh sebagai berikut :

\section{Hasil belajar}

Tabel 3. Hasil belajar siklus I

\begin{tabular}{ccccc}
\hline $\begin{array}{c}\text { Jumlah } \\
\text { siswa }\end{array}$ & Tuntas & $\begin{array}{c}\text { Tidak } \\
\text { Tuntas }\end{array}$ & $\begin{array}{c}\text { Ketuntasan } \\
(\boldsymbol{\%})\end{array}$ & $\begin{array}{c}\text { Rata- } \\
\text { rata }\end{array}$ \\
\hline 25 & 12 & 13 & 48 & 70,24 \\
\hline
\end{tabular}

Hasil belajar siklus I menunjukkan bahwa siswa yang mendapat nilai sama/ diatas KKM (78) dari 25 siswa hanya 12 siswa atau $48 \%, 13$ siswa tidak tuntas atau 52\% dengan rata - rata nilai sebesar 70,24.

\section{Keaktifan Siswa}

Tabel 4. Hasil keaktifan siswa siklus I

\begin{tabular}{|c|c|c|}
\hline Aspek & $\begin{array}{l}\text { Jumlah } \\
\text { skor }\end{array}$ & Prosentase \\
\hline \multicolumn{3}{|l|}{ Membawa buku modul } \\
\hline \multicolumn{3}{|l|}{$\begin{array}{l}\text { kaitannya dengan kompetensi } \\
\text { dasar yang akan diajarkan }\end{array}$} \\
\hline $\begin{array}{l}\text { Membawa wear pack/ pakaian } \\
\text { praktik }\end{array}$ & 20 & $80 \%$ \\
\hline $\begin{array}{l}\text { Membawa kelengkapan alat } \\
\text { tulis }\end{array}$ & 19 & $76 \%$ \\
\hline Bekerja sama dengan kelompok & 19 & $76 \%$ \\
\hline Menyelesaikan tugas mandiri & 13 & $52 \%$ \\
\hline $\begin{array}{l}\text { Aktif menyelesaikan masalah } \\
\text { dengan referensi yang ada }\end{array}$ & 14 & $56 \%$ \\
\hline $\begin{array}{l}\text { Aktif menjawab pertanyaan } \\
\text { teman dan guru }\end{array}$ & 14 & $56 \%$ \\
\hline $\begin{array}{l}\text { Mencatat rangkuman hasil } \\
\text { belajar }\end{array}$ & 15 & $60 \%$ \\
\hline \multicolumn{3}{|c|}{ Rata - rata prosentase : $67 \%$} \\
\hline \multicolumn{3}{|c|}{ Kategori : Cukup } \\
\hline \multicolumn{3}{|c|}{$\begin{array}{l}\text { Simpulan tabel diatas bahwa keaktifan } \\
\text { siswa dalam kegiatan pembelajaran } \\
\text { masih dalam kriteria cukup hanya } 67 \% \text {. }\end{array}$} \\
\hline \multicolumn{3}{|c|}{ Kegiatan pembelajaran guru } \\
\hline \multicolumn{3}{|c|}{$\begin{array}{l}\text { Penilaian kemajuan guru dalam kegiatan } \\
\text { pembelajaran digunakan untuk mengukur } \\
\text { kemampuan guru dalam mengelola kelas. } \\
\text { Tabel 5. Penilaian kinerja guru }\end{array}$} \\
\hline Aspek & & $\begin{array}{ll}\text { lah } & \text { Skor } \\
\text { r } & \text { Max }\end{array}$ \\
\hline
\end{tabular}

\begin{tabular}{llc}
\hline $\begin{array}{l}\text { Kinerja guru dalam menyiapkan } \\
\text { kelas }\end{array}$ & 2 & 4 \\
$\begin{array}{l}\text { Kinerja guru memberikan motivasi } \\
\text { Kinerja guru memberikan apersepsi }\end{array}$ & 3 & 4 \\
$\begin{array}{l}\text { Kinerja guru menjelaskan pelajaran } \\
\text { komputer dan jaringan dasar }\end{array}$ & 3 & 4 \\
$\begin{array}{l}\text { Kinerja guru menjelaskan cara } \\
\text { menginstalasi jaringan dasar sesuai }\end{array}$ & 3 & 4 \\
$\begin{array}{l}\text { SOP } \\
\text { Kinerja guru menerapkan metode }\end{array}$ & 2 & 4 \\
$\begin{array}{l}\text { PBL } \\
\text { Kinerja guru menumbuhkan } \\
\text { partisipasi anak dalam belajar } \\
\begin{array}{l}\text { Kinerja guru dalam berkomunikasi } \\
\text { dengan anak }\end{array}\end{array}$ & 3 & 4 \\
$\begin{array}{l}\text { Kinerja guru membuat kesimpulan } \\
\text { hasil belajar }\end{array}$ & 3 & 4 \\
$\begin{array}{l}\text { Kinerja guru melakukan evaluasi } \\
\text { Kinerja guru dalam menutup } \\
\text { pelajaran }\end{array}$ & 3 & 4 \\
\hline JUMLAH & 3 & 4 \\
\hline RATA - RATA (\%) & 30 & 44 \\
\hline
\end{tabular}

Simpulan hasil penilaian kinerja guru pada tabel diatas menunjukkan mencapai $68 \%$ yang bisa disimpulkan bahwa kinerja guru pada siklus I masuk dalam kategori cukup.

\section{c. Hasil Penelitian Siklus II}

Siklus II merupakan siklus perbaikan dari siklus I yang belum mencapai keberhasilan sesuai yang diharapkan, penelitian ini hampir sama dengan pengamatan pada siklus I.

\section{Hasil belajar}

Tabel 6. Hasil belajar siklus II

\begin{tabular}{ccccc}
\hline $\begin{array}{c}\text { Jumlah } \\
\text { siswa }\end{array}$ & Tuntas & $\begin{array}{c}\text { Tidak } \\
\text { Tuntas }\end{array}$ & $\begin{array}{c}\text { Ketuntasan } \\
(\boldsymbol{\%})\end{array}$ & $\begin{array}{c}\text { Rata- } \\
\text { rata }\end{array}$ \\
\hline 25 & 20 & 5 & 80 & 81,29 \\
\hline
\end{tabular}

Hasil tes akhir siklus II yang terdapat pada tabel diatas bahwa siswa yang mendapat nilai sama/ diatas 78 (KKM) dari 25 siswa sebanyak 20 siswa atau $80 \%$, dan sebanyak 5 siswa nilai di bawah 78 (KKM) atau 20\%. Ini membuktikan bahwa pelaksanaan siklus II dianggap berhasil walaupun belum mencapi $100 \%$ namun telah mencapai indikator keberhasilan yaitu $70 \%$.

\section{Keaktifan Siswa}

Tabel 7. Hasil keaktifan siswa siklus II Jumlah Prosentase 


\begin{tabular}{|c|c|c|}
\hline \multicolumn{3}{|c|}{ skor } \\
\hline Membawa buku modul & \multirow[b]{2}{*}{22} & \multirow[b]{2}{*}{$88 \%$} \\
\hline $\begin{array}{l}\text { komputer dan jaringan dasar } \\
\text { dan referensi lain yang ada } \\
\text { kaitannya dengan kompetensi } \\
\text { dasar yang akan diajarkan }\end{array}$ & & \\
\hline $\begin{array}{l}\text { Membawa wear pack/ pakaian } \\
\text { praktik }\end{array}$ & 25 & $100 \%$ \\
\hline $\begin{array}{l}\text { Membawa kelengkapan alat } \\
\text { tulis }\end{array}$ & 23 & $92 \%$ \\
\hline Bekerja sama dengan kelompok & 20 & $80 \%$ \\
\hline Menyelesaikan tugas mandiri & 21 & $84 \%$ \\
\hline $\begin{array}{l}\text { Aktif menyelesaikan masalah } \\
\text { dengan referensi yang ada }\end{array}$ & 20 & $80 \%$ \\
\hline $\begin{array}{l}\text { Aktif menjawab pertanyaan } \\
\text { teman dan guru }\end{array}$ & 19 & $76 \%$ \\
\hline $\begin{array}{l}\text { Mencatat rangkuman hasil } \\
\text { belajar }\end{array}$ & 23 & $92 \%$ \\
\hline \multicolumn{3}{|c|}{ Rata - rata prosentase : $87 \%$} \\
\hline \multicolumn{3}{|c|}{ Kategori : Sangat Baik } \\
\hline \multicolumn{3}{|c|}{$\begin{array}{l}\text { Simpulan tabel diatas bahwa keaktifan } \\
\text { siswa dalam kegiatan pembelajaran } \\
\text { masih dalam kriteria cukup hanya } 87 \% \text {. }\end{array}$} \\
\hline Aspek & $\begin{array}{l}\text { Jumla } \\
\text { h skor }\end{array}$ & $\begin{array}{l}\text { Skor } \\
\text { Max }\end{array}$ \\
\hline $\begin{array}{l}\text { Kinerja guru dalam menyiapkan } \\
\text { kelas }\end{array}$ & 3 & 4 \\
\hline Kinerja guru memberikan motivasi & 3 & 4 \\
\hline Kinerja guru memberikan apersepsi & 3 & 4 \\
\hline $\begin{array}{l}\text { Kinerja guru menjelaskan pelajaran } \\
\text { komputer dan jaringan dasar }\end{array}$ & 4 & 4 \\
\hline $\begin{array}{l}\text { Kinerja guru menjelaskan cara } \\
\text { menginstalasi jaringan dasar sesuai } \\
\text { SOP }\end{array}$ & 3 & 4 \\
\hline $\begin{array}{l}\text { Kinerja guru menerapkan metode } \\
\text { PBL }\end{array}$ & 3 & 4 \\
\hline $\begin{array}{l}\text { Kinerja guru menumbuhkan } \\
\text { partisipasi anak dalam belajar }\end{array}$ & 4 & 4 \\
\hline $\begin{array}{l}\text { Kinerja guru dalam berkomunikasi } \\
\text { dengan anak }\end{array}$ & 3 & 4 \\
\hline $\begin{array}{l}\text { Kinerja guru membuat kesimpulan } \\
\text { hasil belajar }\end{array}$ & 3 & 4 \\
\hline Kinerja guru melakukan evaluasi & 3 & 4 \\
\hline $\begin{array}{l}\text { Kinerja guru dalam menutup } \\
\text { pelajaran }\end{array}$ & 3 & 4 \\
\hline JUMLAH & 35 & 44 \\
\hline RATA - RATA (\%) & $80 \%$ & $\begin{array}{c}\text { Sangat } \\
\text { baik }\end{array}$ \\
\hline
\end{tabular}

Kinerja guru pada tabel menunjukan mencapai $80 \%$ bisa disimpulkan bahwa kinerja guru pada siklus II masuk dalam kategori sangat baik.

\section{Pembahasan}

Dilihat dari permasalahan di atas peneliti melaksanakan penelitian dengan model siklus, yaitu siklus I yang ternyata hasilnya belum bisa memuaskan karena belum mencapai indikator keberhasilan maka peneliti melanjutkan pada siklus II yang ternyata hasilnya sangat memuaskan meskipun belum mencapai $100 \%$ namun telah melebihi indikator keberhasilan.

\section{Hasil belajar}

Tabel 9. Perbandingan Hasil belajar

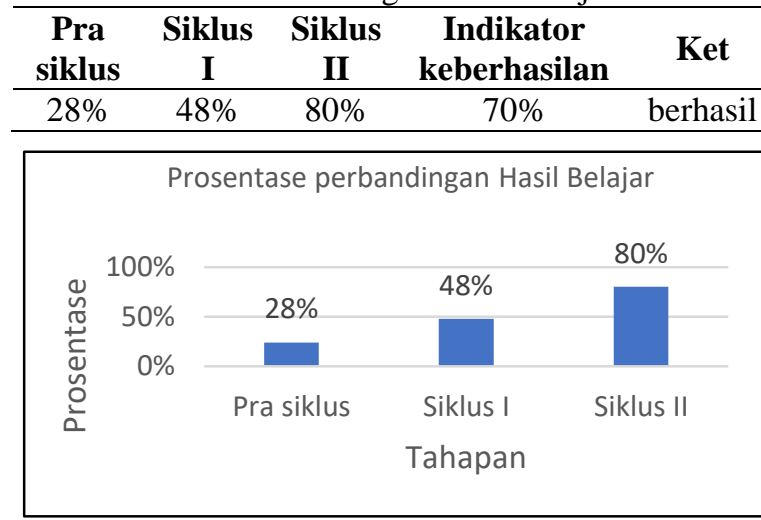

Gambar 3. Grafik perbandingan hasil belajar

Berdasarkan tabel diatas kondisi pada pra siklus menunjukkan bahwa dari 25 siswa hanya 7 siswa (28\%) yang mencapai nilai ketuntasan. Setelah diadakan penelitian pada siklus I menunjukkan adanya peningkatan hal ini dapat dilihat dari hasil belajar siklus I yaitu 12 siswa (48\%) mencapai nilai ketuntasan minimal hal ini menunjukkan peningkatan dari pra siklus yaitu 5 siswa (20\%) namun belum mencapai indikator keberhasilan yaitu $70 \%$. Setelah dilaksanakan perbaikan pada siklus II dapat dilihat peningkatan yaitu 20 siswa $(80 \%)$ yang mencapai nilai ketuntasan minimal ini menunjukkan ada peningkatan 8 siswa $(32 \%)$.

Menurut (Kamdi, 2007: 77) Problem Based Learning adalah suatu model pembelajaran yang melibatkan siswa untuk memecahkan masalah melalui tahap-tahap metode ilmiah sehingga siswa dapat mempelajari pengetahuan yang berhubungan dengan masalah tersebut dan sekaligus memiliki ketrampilan untuk memecahkan masalah.

\section{Keaktifan siswa}


Tabel 10. Perbandingan keaktifan siswa

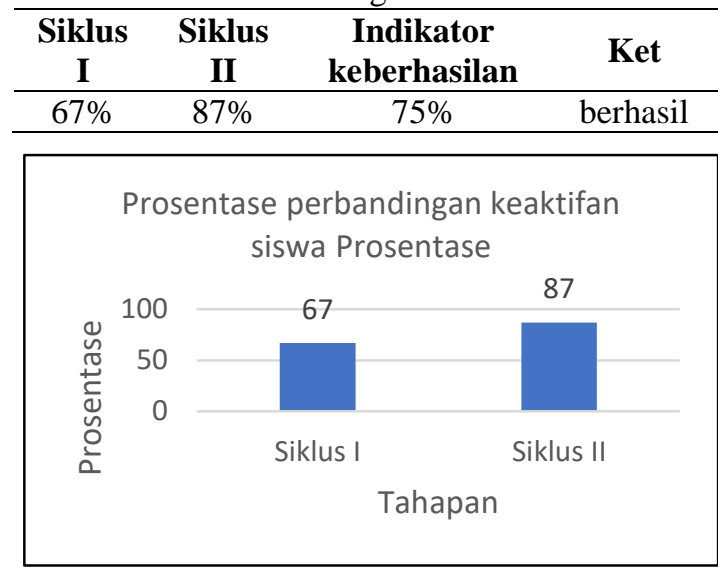

Gambar 4. Grafik perbandingan keaktifan siswa

Dapat dilihat bahwa pada siklus I dan II keaktifan siswa adalah $67 \%$ dan $87 \%$, sehingga keaktifan siswa mengalami peningkatan sebesar $20 \%$.

Diungkapkan Arends (Trianto, 2007), Problem Based Learning merupakan suatu pendekatan pembelajaran dimana siswa dihadapkan pada masalah autentik (nyata) sehingga diharapkan mereka dapat menyusun pengetahuannya sendiri, menumbuh kembangkan keterampilan tingkat tinggi dan inkuiri, memandirikan siswa, meningkatkan kepercayaan dirinya.

\section{Kinerja guru}

Tabel 11. Perbandingan kinerja guru

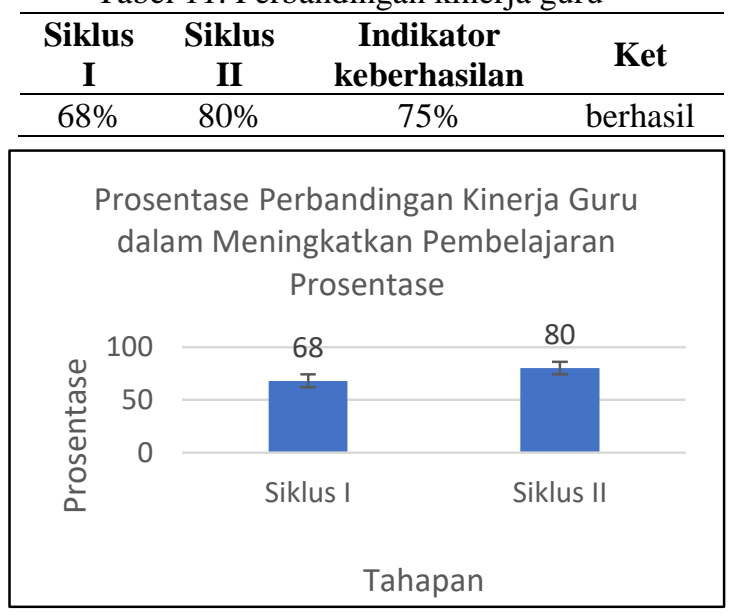

Gambar 5. Grafik kinerja guru

Diketahui bahwa kinerja guru dalam menerapkan model pembelajaran problem based learning pada siklus I dan II yaitu $68 \%$ dan $80 \%$ sehingga kinerja guru mengalami peningkatan dari siklus I ke siklus II yaitu sebesar $12 \%$.

Selaras dengan penelitian yang dilakukan (Mulyasa, 2009: 105) bahwa indikator keberhasilan guru pengampu dikatakan berhasil jika kinerja guru meningkat sekurang - kurangnya $75 \%$ dengan kriteria baik yang meliputi peningkatan profesionalisme guru, sistematika penyajian materi. Penerapkan model pembelajaran yang tepat perlu diperhatikan agar siswa bisa lebih aktif dan terampil dalam pembelajaran dan guru dapat memberikan motivasi terhadap siswa (Pratama, 2018).

\section{PENUTUP}

Berdasarkan analisis yang dilakukan dapat diambil kesimpulan sebagai berikut : (1) Penggunaan model Problem Based Learning dapat meningkatkan pembelajaran pada siswa kelas X TKJ 1 SMK Negeri I Kemusu Boyolali, terbukti dari peningkatan hasil belajar dari hasil pra siklus hanya $28 \%$ menjadi $48 \%$ pada siklus I dan meningkat lagi menjadi $80 \%$ pada siklus II $>$ indikator keberhasilan 70\%. (2) Penggunaan model Problem Based Learning dapat meningkatkan keaktifan siswa pada pembelajaran di kelas, hal ini dapat dilihat dari hasil observasi bahwa prosentase keaktifan siswa yang terus meningkat dari siklus I dan siklus II yaitu $67 \%$ menjadi $87 \%$ dan $>$ dari indikator keberhasilan $75 \%$. (3) Guru dapat menerapkan model problem based learning pada pelajaran di kelas $\mathrm{X}$ TKJ 1 SMK Negeri I Kemusu Boyolali, hal ini dapat dilihat dari hasil observasi/ penilaian kemapuan guru pada siklus I dan siklus II yaitu $68 \%$ menjadi $80 \%$ sehingga kinerja guru mengalami peningkatan dari siklus ke siklus sebesar $12 \%$ dan $>$ dari indikator keberhasilan $75 \%$.

\section{DAFTAR PUSTAKA}


Ahmadi, Abu. (1997:52). Strategi Belajar Mengajar. Pustaka Setia. Bandung

Ali, Muhammad. 1993. Penelitian Kependidikan Prosedur dan Stategi. Bandung: Angkasa.

Arikunto, S. 2005:264. Menghitung.rata rata. Analisis Nilai.

Arikunto, Suharsimi. (2005). Manajemen Penelitian. Jakarta: Rineka Cipta.

Arikunto, S. (2013). Dasar-dasar Evaluasi Pendidikan (Edisi Revisi). Jakarta: PT Bumi Aksara.

Budhi Irawan. 2005. Jaringan Komputer. Bandung: Graha Ilmu

Bruner, J. 1997. The Procesof Education A landmark in educational theory. . Harvad University Press. Dikutip dari Moh.Asrori. 2009. Psikologi . Pembelajaran. Bandung: CV. Wacana Prima

Clements, W. H. 1991. Community responses of stream organisms to heavy metals. Colorado: Univ. Press.

Darmadi, H. (2011). Metode Penelitian Pendidikan. Bandung: ALFABETA.

Darsono. (2000:24). Belajar dan Pembelajaran. Semarang : IKIP Press

Depag RI.(2001:19). Metodologi Pendidikan Agama Islam

Djamaluddin dan Abdullah Aly.(1999:114). Kapita Selekta Pendidikan Islam

Duch. 1995. Pembelajaran Berbasis Masalah. Jakarta: Sejarah Indonesia.

Gagne, Briggs, dan wagner dalam Udin S. Winataputra.(2008) http// metode.pembelajaran.co.id

Gijselaers, W.H. (1996). Conneting Problem-Based Practice with Educational Theory. Dalam Wilkerson, L(Ed). New Direction for Theaching and Learning. No.68. Josey-Bass Publisher

Kasbolah. 1999. Penelitian Tindakan Kelas. Malang: Universitas Negeri Malang.

Kasihani Kasbolah. (1999). Penelitian Tindakan Kelas (PTK). Jakarta :
Departemen Pendidikan dan

Kebudayaan.

Kamdi. 2007. Strategi Pembelajaran. Bandung:PT Remaja Rosdakarya

Kemmis, Stephen \& Mc. Taggart, Robin. (1988). The Action Research Planner. Victoria: Deakin University.

Pratama, A. (2018). Pengaruh Pengajaran Pemrogaman Animasi melalui Aplikasi Scratch pada Kemampuan Pemecahan Masalah. Joined Journal (Journal of Informatics Education), 1(1), 24. https://doi.org/10.31331/joined.v1i1.61 3

Lepinski., (2005), Problem Based Learning: A New Approach To Teaching, Training \& Developing Employees. Cokie Lepinski, Assistant Communications Manager Marin County Sheriff's Office. Sugiyono. 2011. Metode Penelitian Kuantitatif, Kualitatif, dan R\&D. Bandung: Alfabeta.

Suyanto. (2009). Urgensi Pendidikan Karakter. Direktorat Jendral Pendidikan Dasar Kementrian Pendidikan Nasional

Suyanto, Ph.D. 2010.Model Pembinaan Pendidikan Karakter Di Lingkungan Sekolah. Jakarta : Dirjen Dikdasmen Direktorat Pendidikan Dasar Dan Menengah Kementerian Pendidikan Nasional.

Syah, M. (2011). Psikologi Belajar. Jakarta: Raja Grafindo Persada.

Sarwiji Suwandi. 2008. Penelitian Tindakan Kelas (PTK) dan Penulisan Karya Ilmiah. Surakarta: Panitia Sertifikasi Guru Rayon 13.

Trianto, (2007). Model-model Pembelajaran iInovatif berorientasi kontruktivistik. Prestasi Pustaka: Jakarta.

Trianto. 2010. Model Pembelajaran Terpadu Konsep, Strategi, dan Implementasinya dalam KTSP. Jakarta: Bumi Aksara

Winataputra, Udin S. dkk. 2008. Teori Belajar dan Pembelajaran. Jakarta: Universitas Terbuka. 
WJS. Poerwadarminta.1999:767. Kamus Besar Bahasa Indonesia. 